\title{
With reasons of the heart before God. \\ On religious experience from \\ an evolutionary-theological perspective ${ }^{1}$
}

NGTT DEEL 55, NO 1, 2014

\section{Veldsman, DP}

Dept. of Dogmatics and Christian Ethics

University of Pretoria

\section{ABSTRACT}

What does the affective-cognitive dimension of being human entails? Many contemporary scholars from theological (especially religious experience) perspectives as well as from evolutionary biological (especially neuroscientific) perspectives have made exciting inroads in the on-going anthropological discourses on this very dimension of being human. My article partially makes work of their respective contributions. For the former theological perspective I will utilize Pascal and Stoker. For the latter neuroscientific perspective I will concentrate on LeDoux and Damasio. I call my contribution an evolutionary-theological re-conceptualisation of religious experience for which I make use of Pascal's famous words from his Pensées (1670) "The heart has its reasons which reason does not know" and "(i)t is the heart which experiences God and not the reason". Therefore the title: With reasons of the heart before God. Such a formulation however immediately raises the question: Does such an emphasis on the "heart" reintroduce irrationality into the scientific scholarly dialogue? The answer is clear: Yes, it does. It is argued that it should be re-introduced constructively into contemporary science-theology discourses in order - on the one hand - to critically address the very accusation, and - on the other hand - to present us with a far richer, deeper understanding of personhood. From the constructive integration of the two perspectives, namely the theological and neuroscientific the words of Pascal is finally re-formulated from an evolutionary-theological perspective and qualified in which emotion is presented as the embodiment of the logic of survival.

1 Paper that was read at $15^{\text {th }}$ European Society for Studies in Science and Theology Conference, Do Emotions Shape the World?, Assisi, Italy 30 April - 4 May 2014 has been re-worked for publication as article.

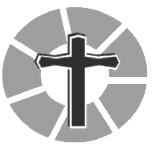




\section{INTRODUCTION}

No aspect of our mental life is more important to the quality and meaning of our existence than emotions. They are what make life worth living, or sometimes ending (De Sousa 2013:1).

The theme for the 15th European Society for Studies in Science and Theology Conference in Assisi, Italy in April 2014 was formulated as a question, namely "Do emotions shape the world?" My opinion of the conference question was that it was formulated too tidily and too cautiously. The more robust question - however still tidily formulated - should rather have been: What are the implications of a world shaped by emotions? Or perhaps reformulated with a specific anthropological focus: What does an affective-cognitive understanding of personhood entail? If we would agree from a hermeneutical perspective that all experience is interpretative experience and thus theory-laden, will we constructively agree in the same manner from an evolutionary biological perspective that all experience is shaped by emotions and is thus "affective-laden"? I would like to argue from an evolutionary biological perspective that this is an anthropological given! There is in my opinion indeed no polite way around the constitutive shaping-character of emotions in our respective worlds. ${ }^{2}$ Let me take as vantage point for my argument the conclusion of Ronald De Sousa $(2013)^{3}$ in his very useful article on "Emotion" in The Stanford Encyclopaedia of Philosophy. He writes:

- Emotions are typically conscious phenomena; yet

- Dispositions to manifest certain emotion types, such as irascibility, are often unconscious;

- Emotions typically involve more pervasive bodily manifestations than other conscious states; but

- They cannot reliably be discriminated on physiological grounds alone;

- Emotions vary along a number of dimensions: intensity, duration, valence, type and range of intentional objects, etc.;

- They are typically, but not always, manifested in desires;

- They are distinct from moods, but modified by them;

- They are reputed to be antagonists of rationality; but also

2 Most probably the best known classic and influential example is that from the $4^{\text {th }}$ century BC of Plato's Chariot Allegory in Phaedrus.

3 Ronald de Sousa is an Emeritus Professor at the Department of Philosophy of the University of Toronto, Canada. 
- They play an indispensable role in determining the quality of life;

- They contribute crucially to defining our ends and priorities.

I cannot unpack and unravel in any extensive discursive way in this article the archaeological depth and interdisciplinary width of all of these statements by De Sousa, but I would like to address at least his following two statements, namely that emotions firstly are "distinct from moods, but modified by them" and that they secondly "are reputed to be antagonists of rationality". The popular and very influential belief is that emotion and rationality stand in opposition to each other. Furthermore those emotions are but inner feelings or sensations that reflect only physiological causal connections to the objects. I would like to argue two points, namely to refute the popular convictions of Emotion vs. Rationality, and secondly to present a viewpoint of layered affectivity in which affectivity involves more than emotion. My aim in this article is - summarised - in short:

The affective-cognitive dimension of being human - that is, of being persons of flesh and blood - represents a constitutive dimension of personhood that enriches a holistic understanding of life. My statement simply re-introduces and emphasises that which many contemporary scholars from theological (especially religious experience) perspectives as well as from evolutionary biological (especially neuroscientific) perspectives have already noticed and defended in their respective and distinctive contributions to anthropology. I make work of their contributions in my exposition. For the latter neuroscientific perspective I will concentrate on LeDoux and Damasio. For the former theological perspective I will utilize Pascal and Stoker. But before I discuss them, I would like to give firstly a brief explanation for the choice of "heart" in my title, and secondly a short discussion of the recently published critique Het brein geeft te denken $(2012)^{4}$ by the Dutch theologian Gijs Dingemans ${ }^{5}$ on "brainification".

\section{THE HEART: METAPHORIC DESCRIPTION OF THE SEAT OF HUMAN LIFE}

Humans are the way that life knows life (cf Veldsman 2013:8ff). ${ }^{6}$ In their knowing of life, the most distinct and significant characteristic of human life or personhood is

4 The title can freely be translated as: "To reflect on the brain".

5 Gijs Dingemans is an Emeritus Professor of the Department of Practical Theology of the University of Groningen, The Netherlands

6 My formulation goes back to the reference by the British theologian and philosopher of the University of Nottingham, Conor Cunningham in his Darwin's Pious Idea (2010) of George Wald who said that the way for an atom to know an atom, is a physicist! 
its discovering, explicating and unfolding of meaning - in so many different ways as broad as the spectrum of life itself - in its interaction with reality. One of the most powerful metaphoric descriptions for one of the most significant dimensions of the quest of human life on its journey in search of and explicating meaning in my opinion is the heart. The heart as the seat of human life. The heart as the fountain of meaning. Of personhood. Just as the physiological (biological) body cannot be alive without the heart as the organ that "pumps blood", in the same metaphoric manner we cannot talk about life if not "pumped" by meaning in whatever cultural-philosophical and psycho-sociological manner it finds historical-contextual reflective expression. But then not only meaning in reference to its cognitive dimension, but specifically adding the affective dimension - as heart - to cognitive meaning-formation. The heart as metaphoric descriptive term for the seat of life, thus of the blending of knowledge and emotions (affectivity), unleashes a cosmological-existential and poetic depth and width and height for reflection on all of life whether human or non-human. ${ }^{7}$

If the heart - as the metaphoric depiction of the in one of the cognitive and affective dimension (mind-heart) of being human - represents the seat of life, where does the brain fit in? Posing this intermediate question is of importance since there are contemporary anthropological discourses that focus primarily on our brains (mind without heart!) as constitutive dimension of being characterized as a rational human being!

\section{3. "BRAINIFICATION"?}

The Dutch scholar Gijs Dingemans has in his recent book "Het brein geeft te denken" (2012) very neatly critiqued the popular and influential rationalistic and reductionistic anthropological perspectives that suggest, "We are our brains"! Although he mostly covers Dutch neuroscientific literature ${ }^{8}$ in his critique, it is

7 The heart as descriptive term is in so many multi-various ways part of the everyday vernacular in all fields of being human (literature, music etc) that examples seem to be superfluous. Perhaps just one example to illustrate my choice for poetic. It comes from the beautiful formulation by Plato: "Every heart sings a song, incomplete, until another heart whispers back. Those who wish to sing always find a song. At the touch of a lover, everyone becomes a poet".

8 Some of the most recent important Dutch publications that he mentions are: Lone Frank De vijfde revolutie - omdat hersenwetenschap onze wereld gaat veranderen (2010); Victor Lamme, De vrije wil bestaat niet; over wie er echt de baas is in het brein (2010); Dick Swaab, Wij zijn ons brein - van baarmoeder tot Alzheimer (2010); Margriet Sitskoorn, Het maakbare brein; Ge-bruik je hersens en word wie je wilt zijn (2008); Margriet Sitskoorn, Passies van het brein. Waarom zondigen zo verleidelijk is (2009); H. 
representative of the most popular arguments that we find worldwide in defence of the all-encompassing importance of the brain and cognition. From there the critical coined Dutch term "breinificatie" ("brainification") as protest against those viewpoints that want to suggest "we are our brains"! With the conviction that "we are our brains" (Swaab) comes the negation of the "free will" of humans (Lamme). For Dingemans, these suggestions - which he takes very seriously - represent a new challenge that comes from the neurosciences and that are directed at the philosophers, theologians, psychologists and every one with a "frontale hersenkwab" (frontal brain lob)! His main concern in addressing "brainification" as challenge is to answer the question: Does my "I" actually exist, or is my "I" only a product of my biological and environmental factors? And with that comes a second related question: How is the relationship between our feelings, emotions and mind to be understood? For Dingemans we are "more than our brains", and he defends his position in following amongst others Sicco de Jong and system-theory that argues that we have to work with the "living person", the "total system (and all the subsystems) as human being". We are on the one hand made up (inside) by these systems and subsystems - that can be studied on their own - but we exist at the same time - on the other hand in continuous reaction to many systems of the world "outside of us". It is surely not only the interaction with everything that has been collected by and in our brains, but also with the environment that we find ourselves in. Being human - as identity, psyche and spirit - is some kind of "counting together" ("optelsom") in various languages ${ }^{10}$ of all of these that are more than our biological and neural make-up. ${ }^{11}$ For Dingemans it entails a new religious understanding and working out of these very neuroscientific insights in their respective languages of personhood. To a more

van Praag, God en Psyche (2008); Bert Keizer, Waar blijft de ziel? (2012), Marc Slors, Dat had je gedacht! Brein, bewustzijn en vrije wil in filosofisch perspectief (2012).

9 The word "breinificatie" is a word "made up" in Dutch which can roughly be translated into English as "brainification", that is, human existence reduced to the workings of the (autonomous) brain (cf Dingemans 2012:12).

10 The reference to various languages is to the distinct languages of respectively the natural sciences, of philosophy, of psychology, of religion etc!

11 The important question that Dingemans as theologian raises is the anthropological question whether we are "from nature" sinful and not destined to do good. He addresses the question in taking the neuroscientific input seriously. In my opinion he creatively argues that being human entails being confronted with three distinct conflicts that must be discerned - namely, the internal conflict of emotion and ratio, moral conflict to choose between right and wrong, and religious conflict (accepting that we cannot save ourselves). 
detailed "counting together" specifically of emotion and rationality I would like to turn to.

\section{EMOTION VS RATIONALITY}

As starting point, I deliberately choose the French mathematician, physicist and theologian Blaise Pascal (1623-1662) and his famous words from his posthumously published Pensées (1670) "the heart has its reasons which reason does not know" and "(i)t is the heart which experiences God and not the reason". ${ }^{12}$ These rich Pascalian words I would like to revisit from an evolutionary-theological perspective.

My choice for the heart metaphor (Pascal) immediately raises the question: Does such an emphasis on the "heart" re-introduce irrationality ${ }^{13}$ - often the common accusation (eg John Locke, David Hume, Rene Descartes) - into the scholarly dialogue? Yes, it does and this is precisely the reason for introducing it! For it is to be argued that it should be re-introduced constructively into contemporary science-theology discourses in order - on the one hand - to critically address the very accusation of irrationality, and - on the other hand - to present us with a far richer, deeper understanding of personhood. To respond and to refute accusations of irrationality, we have to critically revisit viewpoints on emotion that understand emotion as an inner feeling or sensation that reflects only a physiological causal connection to the object.

Over against such an understanding of emotion which leads to its characterisation as irrational, I take my vantage point from evolutionary biology - amongst others from the very insightful classic contributions ${ }^{14}$ of the American neuroscientist Joseph

12 The references are from the translation by William Finlayson Trotter of Pascal's [1954 (1670):78] Pensees.

13 Nor is it some kind of immunisation strategy, that is, an effort to avoid any form of being held accountable for a viewpoint.

14 I have chosen the works of LeDoux and Damasio simply for being so influential after being published. Their respective contributions were met with wide-ranging scholarly appraisal. LeDoux's The Emotional Brain (1996) - just to mention a few examples - was described by Daniel Goleman as a "superb guide to that ultimate frontier in understanding our emotional life, the brain.... He calls it “...pioneering state-of-theart research". Howard Eichenbaum states that "LeDoux succeeds in unraveling the mysteries of The Emotional Brain". Steven Hyman says that "LeDoux shows how the study of the brain leaves our understanding of emotion richer than it was before". Walter Mischel calls it "an impressive, fact-filled, provocative overview of the state of the art and science in the demystification of The Emotional Brain". Eric Kandel describes it as a "marvelous book" in which "LeDoux guides us in a masterly way through the current 
LeDoux in his The Emotional Brain (1996) and Portuguese-American neurobiologist Antonio Damasio in his The Feeling of What Happens (1999) - that present us with new insights on the affective dimension of personhood, especially that our emotions are rooted in our biological nature. Unfortunately only a few key insights from their respective creative contributions are noted in the following exposition.

\subsection{Joseph LeDoux and The Emotional Brain (1996)}

...(M)inds without emotions are not really minds at all. They are souls on ice - cold lifeless creatures devoid of any desires, fears, sorrows, pains, or pleasures (LeDoux 1996:25).

According to James McGaugh, a neurobiologist at the University of California in Irvine, "Joe LeDoux is among a small number of people pushing the frontiers of how the brain provides a basis for our emotional responses". In response LeDoux who entered graduate school with virtually no training in biology - said: "I wasn't corrupted by too much knowledge... I was naive enough to think that emotions could be studied". And when studied, one has to know that there "...is no such thing as the 'emotion' faculty and there is no single brain systems dedicated to this phantom function" (LeDoux 1996:16). One has also to know that the human brain

...happens to be the most sophisticated machine imaginable, or unimaginable, yet it wasn't predesigned. It is the product of evolutionary tinkering, where lots of little changes over extremely long periods of time have accumulated (LeDoux 1996:104).

Through LeDoux's "naivety" in studying the evolutionary established links between the brain's structure and emotions, we are insightfully confronted by the questions: What happens in our brains to make us feel fear, love, hate, anger, joy? Do we control our emotions, or do they control us? Is being hungry an emotion or not?

thinking about emotion, from both a behavioral and neurobiological perspective, in a clear and entertaining style that is accessible to all. The Emotional Brain gives us a new and deeper sense of our own emotional life". In very much the same manner, Damasio's The Feeling of What Happens (1999) enjoyed a similar choir of appraisal. To mention only a few. Williford described it as a "... landmark work ... and essential read"; Dolan in Nature calls it a "stunning" book which he later qualifies as a "remarkable work of intellectual daring"! Mainen says that Damasio's contribution is a "radical rejection of conventional thinking" whereas Grof sees Damasio's contribution as "an amazing synthesis of precise experimentation and poetic thinking". Oatley simply calls it a "terrifically good book"! 
Do animals have emotions? LeDoux ${ }^{15}$ investigates the origins of human emotions and explains that many exist as part of complex neural systems that evolved to enable us to survive. For him, emotions are a "subjective experience, a passionate invasion of consciousness, a feeling” (LeDoux 1996:267). Unlike conscious feelings, emotions originate in the brain at a much deeper level. ${ }^{16}$ Emotions can occur without cognitive processing in the cortex. For example, our brains can detect danger before we even experience the feeling of being afraid. The brain also begins to initiate physical responses (heart palpitations, sweaty palms, muscle tension) before we become aware of an associated feeling of fear. Conscious feelings, says LeDoux, are somewhat irrelevant to the way The Emotional Brain works. He points out that emotional responses are hard-wired into the brain's circuitry, but the things that make us emotional are learned through experience. And this may be the key to understanding, even changing, our emotional make up. LeDoux's research, using an array of neurobiological methods, centres on the amygdala, a small area hidden within the temporal region of the brain. According to LeDoux's evidence, this area is the heart of the emotion system. It is able to process the emotional significance of individual stimuli as well as complex situations. The amygdala is, in essence, involved in the appraisal of emotional meaning. Appraisal - the comparison of an event to a person's goals and resources - is the process that cognitive researchers agree is the key to how particular emotions are produced in response to particular kinds of events. ${ }^{17}$

From these brief notes on LeDoux, I turn to Damasio.

15 I would like to acknowledge my indebtedness to Keith Oatley, professor of Applied Psychology at the University of Toronto for a number of these formulations that follow in my explication of the significance of LeDoux's work.

16 For LeDoux, there are similarities and differences between our conscious emotions and our conscious thoughts. He explains: "Conscious emotional feelings and conscious thoughts are in some sense very similar. They both involve the symbolic representation in working memory of subsymbolic processes carried out by systems that work unconsciously. The difference between them is not due to the system that does the consciousness part but instead is due to two other factors. One is that the emotional feelings and mere thoughts are generated by different subsymbolic systems. The other is that emotional feelings involve many more brain systems than thought" (LeDoux 1996:299).

17 The interesting concept that LeDoux coins to explain the workings of appraisals, is that off the working memory. He states: "I'm saying that feelings come about when the activity of specialized emotion systems gets represented in the system that give rise to consciousness, and I'm using working memory as a fairly widely accepted version of how the latter might come about" (LeDoux 1996:282). 


\subsection{Antonio Damasio and The Feeling of What Happens (1999)}

Throughout most of the twentieth century, emotion was not trusted in the laboratory. Emotion was too subjective, it was said. Emotion was too elusive and vague. Emotion was at the opposite end from reason, easily the finest human ability, and reason was presumed to be entirely independent from emotion. This was a perverse twist on the Romantic view of humanity. Romantics placed emotion in the body and reason in the brain. Twentiethcentury science left out the body, moved emotion back into the brain, but relegated it to the lower neural strata associated with ancestors who no one worshiped. In the end, not only was emotion not rational, even studying it was probably not rational (Damasio 1999:39).

From the onset in his rational study of emotion, Damasio is clear that the feeling of what happens, self-consciousness and emotion go together. Rationality and emotion go together. Of the "feeling of what happens" as self-consciousness, emotion constitutes "... a support system without which the edifice of reason cannot operate properly" (Damasio 1999:42). It is from this closely knitted understanding of the relationship between rationality and emotion within the broader framework of life ${ }^{18}$ that Damasio (1999:312-3) states:

...(C)onsciousness feels like a feeling, and if it feels like a feeling, it may well be a feeling. It certainly does not feel like a clear image in any of the externally directory sensory modalities. It is not a visual pattern or an auditory pattern; it is not an olfactory or gustatory pattern. We do not see consciousness or hear consciousness. Consciousness does not smell or taste. Consciousness feels like some kind of pattern built with the nonverbal signs of body-states. It is for this reason perhaps that the mysterious source of our mental first-person perspective - core consciousness and its simple sense of the self - is revealed to the organism in a form that is both powerful and elusive, unmistakable and vague.

Damasio identifies two problems of consciousness. ${ }^{19}$ The first is to explain how neural patterns engender mental "images", where an image is not just a visual

18 Damasio (1999:135) refers elsewhere to the broader framework of life in which "consciousness" is embedded as follow: "...(C)onsciousness has succeeded in evolution because it supports life most beautifully".

19 The significance of consciousness is spelt out by Damasio (1999:304) as follow: “...(T) he power of consciousness comes from the effective connection it establishes between the biological machinery of individual life regulation and the biological machinery of thought. That connection is the basis for the creation of an individual concern which 
percept but any mental pattern built with the tokens of each sensory modality. The second problem of consciousness is to explain how we come to have "a sense of self in the act of knowing" (Damasio 1999:9). Damasio is concerned almost exclusively with the latter problem of which he believes that there is no consciousness that is not self-consciousness, ${ }^{20}$ and especially with its relation to the knowledge or feeling of emotions. ${ }^{21}$ Self-consciousness as "core consciousness" is a secondorder state of the mind/brain located in some specific regions that is capable of representing the relation between representations of objects and representations of the soma, while the latter is almost invariably reacting emotionally to some object or another. Feeling is for him the realisation of a nexus between an object and an emotional body state. Damasio further distinguishes core consciousness, which is concerned with the here and now, from extended consciousness, which includes autobiographical memory and the perception of time. His method of inquiry is to advance theoretical hypotheses as suggested and supported by clinical and anatomical evidence. The emotions ${ }^{22}$ are defined as patterns of chemical and neural responses, the function of which is to assist the organism in maintaining life by prompting adaptive behaviours. ${ }^{23}$ They are due to the activation of a set of brain

permeates all aspects of thought processing, focuses all problem-solving activities, and inspires the ensuing solutions. Consciousness is valuable because it centers knowledge on the life of an individual organism" (Damasio 1999:304). It is against this background that he formulates in his own special manner the first problem of consciousness: “... (The) first problem of consciousness is the problem of how we get a 'movie-in-thebrain' provided we realize that in this rough metaphor the movie has as many sensory tracks as our nervous systems have sensory portals..." (Damasio 1999:9; cf 1999:313). The question that Damasio subsequently pursue is specifically the "sense of the self".

20 For Damasio, all living organisms have "proto-selves". However, only organisms with a complex nervous system capable of "seeing" their proto-self interacting with the world also have real "consciousness". These organisms are capable of registering the "feeling of what happens". Human consciousness is one further step beyond, enabled by the fact that we have a large memory that allows autobiographical memory.

21 In the following exposition I have also made use with gratitude of Aldo Moca's helpful review article of Damasio's book.

22 The six primary or universal emotions that are identified are happiness, sadness, fear, anger, surprise, and disgust.

23 Two further distinctions are important, namely secondary and background emotions. Firstly. Secondary and social emotions are also identified, namely embarrassment, jealousy, guilt and pride. Secondly. A class of background emotions such as well-being or malaise, calm or tension, fatigue or energy, anticipation or dread. In the background emotions, the inducer is normally internal and the focus of response is mainly the "internal milieu" of the body. 
structures, most of which also monitor and regulate bodily states around optimal physiological values, in processes known as homeostasis or homeodynamics. The emotions are biologically determined, stereotypical, and automatic, although it is acknowledged that culture and individual development may influence the set of inducers and can inhibit or modify overt expressions. There are rather well defined brain regions responsible for emotion. The brain regions that account for emotions are the amygdala (the centre of the triggering event) and the hypothalamus (the centre of the execution). The physiology of emotion is not easily described, because of the simultaneous activation of several structures and feedback reactions among them. This prevents the process from being straightforwardly linear and creates significant problems for an overall conceptualisation of levels or orders of processing. Damasio distinguishes feelings and emotions: a feeling is a mental representation of the state of the organism's body, the perception of body state, whereas an emotion is the reaction to a stimulus and the associated behaviour (eg. a facial expression). So the feeling is the recognition that an event is taking place, whereas the emotion is the visible effect of it. Emotions are bodily things, while feelings are mental things. Emotions are an automatic response. They don't require any thinking. They are the fundamental mechanism for the regulation of life. Emotions precede feelings, and are the foundations for feelings. Evolution has prepared us with a repertory of emotions that we apply to the circumstances. The effect of the emotion is both some bodily behaviour and the creation of a neural map. That neural map leads to the feeling, and the relationship between maps and feelings is that feelings reflect how well the body is doing according to the map. Neural maps of body states are useful to manage the body. Feelings allow us to reason about the cause of the emotion. Feelings allow us to see the big picture, not just to react mechanically to a situation. An emotion is registered by the brain when a stimulus is recognised as useful for survival or for well being or damaging for survival and well-being. This appraisal results in bodily changes, such as quickening heart-beat, tensing muscles, etc. These bodily changes also imply that a map changes in the brain, and this change is the physical implementation of the "feeling".

From Damasio and the neuroscientific contribution I now turn to Stoker and the religious contribution to address the two statements (by De Sousa) that I chose to focus on, namely that emotions are

- "Distinct from moods, but modified by them" and

- Emotions "are reputed to be antagonists of rationality". 


\section{STOKER, AFFECTIVITY AND COGNITIVITY}

The Dutch philosopher of religion, Wessel Stoker ${ }^{24}$ argues in his Is Faith Rational? (2006) that to address the accusation of the irrationality of emotion, we have to refute those viewpoints on emotion that take emotions only to be an inner feeling or sensation that stands in a physiological-causal relationship. In these (unacceptable) viewpoints, hunger and anger are understood sui generis. Emotions are not tied with any idea (that is, cognitive content) or judgment (that is, any specific cognitive activity).

In the light of the afore going exposition of the neuroscientific contributions of LeDoux and Damasio, it is possible to develop and revise Stoker's (cf. 2006:166ff) philosophical-religious viewpoint and critique in more detail:

- Our emotions are rooted in our biological nature. They have evolved over centuries from the basic instincts relating to mating, protection of territory, food, survival etc. and thus have an (evolutionary) cognitive core.

- Emotions are communicated nonconsciously and consciously by means of various different bodily systems and subsystems, consisting of neural networks and the blood network / stream.

- Three components are distinguished in those theories on the origin of emotion that take their vantage point from their biological rootedness, namely the physiological and / or psychological state-of-mind component of the person experiencing the emotion, the object of the emotion and the relevant reasons for the emotion (Stoker). Emotions thus have mental/cognitive and physical components.

- There is however more to affectivity than emotions. Affectivity refers to every aspect relating to our feelings, emotions and moods. Following Strasser, Stoker (2006:178ff) argues in his exposition of religious affectivity for a layered perspective of emotions. According to this viewpoint, mood represents the deepest, undifferentiated layer of affectivity. ${ }^{25}$

- Mood exposes / lays bare our existence, that is, "our thrownness in existence" (Stoker 2006:180). As "pure feeling", it represents our "finding of being in the

24 Prof Stoker is an Emeritus professor of the Faculty of Theology of the Free University, Amsterdam, The Netherlands.

25 See Stoker's (2006:180ff) broader elaboration on mood regarding its pre-intentional character. Especially illuminating is the image of the fountain - following Strasser - in his exposition of the layerdness of emotion. 
world", or a specific "felt state of mind, pure being-in-the-mood" (Strasser quoted by Stoker 2006:180). It represents a characteristic of being human that expresses our belonging to existence. ${ }^{26}$ Stoker (2006:179) remarks:

Not only emotion but also mood influences our rational thought and our behaviour. The human being is a whole of bios, pathos and logos. Viewing affectivity as layered is an attempt to do justice to the different aspects of our humanness.

$\operatorname{Mood}^{27}$ (and thus our undifferentiated feelings of belonging) and emotions converge ${ }^{28}$ in our thoughts and actions in our hearts. Feeling internalises and personalises "my thoughts" / knowledge (see "Appraisals" and "Emotions create neural maps"). This all takes place in the heart! The heart unites and integrates what reason / knowledge

26 Stoker (2006:181) carefully formulates and differentiates: "This feeling of belonging to being is the ontological feeling. Just like a psychological feeling, it is affectively charged but differs from the former in that it indicates a property of our humanness: our connection with our (life) world. It is a basic feeling of the human being".

27 The collection of undifferentiated emotions Damasio (cf 1999:48) calls "backgroundfeelings". This is very much the same as what Stoker calls "mood". Damasio elaborates on these feelings, stating that it is difficult to distinguish between them. He however continues in this regard with a description of the person who appears to be "tense", "depressed", or "excited" since we "detect background emotions by subtle details of body posture, speed and contour of movements, minimal changes in the amount and speed of eye movement and in the degree of facial muscles" (Damasio 1999:52). The perceived reactions are "closer to the inner core of life" of the one experiencing it and "define our mental state and color our lives" (Damasio 1999:286). In this context mood can be more closely described as consisting of "modulated and sustained backgroundfeelings as well as modulated and sustained feelings of primary emotions..." (Damasio 1999:287). And it is - finally - as "nonconscious system ... deeply interwoven with the conscious reasoning system" (Damasio 1999:302). We do not need to be conscious of the inducer of an emotion and are often not, and we cannot control emotions willfully. You may find yourself in a sad or happy state, and yet you may be at loss as to why you are in that particular state now". And: All emotions use the body as theater..., but emotions also effect the mode of operation of numerous brain circuits: the variety of the emotional responses is responsible for profound changes in both the body landscape and the brain landscape. The collection of these changes constitutes the substrate for the neural patterns which eventually become feelings of emotions" (Damasio 1999:51-2).

28 For a more detailed description of the reciprocal interaction between mood and emotions, see Stoker (2006:182). He poetically formulates: "Moods supply the leitmotif of the song, whereas feelings such as emotions are the changing melody" (Stoker 2006:182). 
separates and / or fragmentises (cf. Stoker 2006:184). This is what the affectivecognitive dimension of being human or personhood according to Stoker entails and which I would to like to support in the light of the afore going expositions of LeDoux and Damasio on emotions. From their respective viewpoints on emotions, they physiologically spell out how Pascal's "reasons of the heart of which reason does not even know" can be evolutionary re-conceptualised from our biologically rootedness. In the words of LeDoux (1996: 33):

...(P)eople normally do all sorts of things for reasons they are not consciously aware of (because the behaviour is produced by brain systems that operate unconsciously) and that one of the main jobs of consciousness is to keep our life tied together into a coherent story, a self-concept.

Thus: "Doing all sort of things for unconscious reasons" on the one hand, and emotions on the other hand as evolutionary ingredient of the conscious "keeping our life affectively-cognitively tied together into a coherent story" thus not only unavoidably shape our life (worlds), but is constitutive of the quality and meaning of our existence that indeed "makes life worth living, or sometimes ending" (De Sousa 2013:1). What are the implications for our perspectives on personhood, and on our understanding of religious experience?

\section{NOTING A FEW IMPLICATIONS}

There are a number of implications from the afore going neuroscientific insights that we can no longer neither ignore nor avoid in our making sense of personhood and of religious experience. Our emotions are biologically rooted. Our emotions operate unconsciously. Our emotions are consciously registered as feelings. Our emotions form part of our affective dimension (feelings, emotions and mood) and are layered. Emotion constitutes a support system without which the edifice of reason cannot operate. Our emotions - and I regard this as one of the most profound insights represent the evolutionary embodiment of the logic of human survival. All of these insights - and more - can be captured in the shorthand description of the affectivecognitive dimension of personhood. Can be hermeneutically characterized in the statement of the affective ladeness of rationality. This is my qualified and explanatory answer to the two statements by De Sousa that I chose to address (see opening paragraph), namely that emotions are "distinct from moods, but modified by them" and that they "are reputed to be antagonists of rationality". The former question finds expression in the formulation of the "layerdness of emotion" and the latter in the affirmation of the affective-cognitive dimension of personhood. Together they find expression in this argumentative context in the words of Pascal, namely as 
"the reasons of the heart"! How then are these "reasons of the heart" to be further theologically explicated as religious experience from an evolutionary perspective?

There are in my opinion a number of interpretative directions in which these words can be explored:

- If emotions embodied the logic of survival, what does it entail for personhood and for religious experience? Should it be pursued and explicated - to give but one possible example - along the lines of Frans de Waal's "Age of empathy" (2009). That is, survival of being human along the lines of compassion, kindness, generosity? In my opinion, this represent a very exciting and deep possibility to unfold and understand the Christian message along the anthropological lines not of the survival of the strongest (which we already know is surely not true), nor survival of those that merely adapt the best to their environment and circumstances (which we do know is very important) but survival of those that "take care" (which we now know present us with a deep biological and profound religious insight).

- Turning to emotions (the heart) and religious experience (and taking the Christian religion as example), numerous revisionary questions come to the fore. If Pascal's famous words "the heart has its reasons which reason does not know" and "(i)t is the heart which experiences God and not the reason" are re-conceptualised from an evolutionary perspective for religious experience as "the mind-heart" that experiences God, what are - to electively name a few the implications for:

- A fundamental anthropological revision of the traditional problematic viewpoints on "original sin". One such very creative possibility to reconceptualise original sin from a neurobiological perspective comes with what Damasio (1999:229) calls the "autobiographical memory". According to him the autobiographical memory "develops and matures under the 'looming shadow' of an inherited biology". Perhaps the best biological description of "original sin"?

- We will simply have to accept from our biological make-up: That humans - given our biological-evolutionary make-up - are inclined to doing good and bad things!

- That - to put it in dogma-historical terms - both Augustine and Pelagius had it right. There are life situations in which our ability to choose are greatly (completely?) impaired by our biological make-up. But at the very same time there are life situations in which we are very capable of making 
free - and responsible - decisions. It is thus now our responsibility to discern between these two.

These are but a few of the exciting interpretative directions and avenues that are opening up from these evolutionary insight from the affective-cognitive dimension of personhood and the affective ladeness of all experience, and thus also of religious experience. Emotions as the "embodiment of the logic of survival" especially deepen and enrich the existential significance of religious experience. Emotions as the (unconscious and conscious) support system without which the edifice of reason cannot operate properly. Weaving these insights together leaves us with no other conclusion that emotions do not only shape our (life)worlds. It represents an important dimension of being human that finds expression in characterizing personhood as affective-cognitive in the act of making sense of being human and of religious experience as "loving God with our hearts" (Pascal).

\section{BIBLIOGRAPHY}

Blakeslee, S 1996. Dr. Joseph LeDoux: Using Rats to Trace Routes of Fear. New York Times Online, 5 November 1996. http://www.cns.nyu.edu/home/ledoux/the emotional brain/book time reviw.htm

Damasio, AR 1999. The Feeling of What Happens. Body and Emotion in the Making of Consciousness. New York: Harcourt Brace \& Company.

De Sousa, R 2013. “Emotion”, The Stanford Encyclopedia of Philosophy (Spring 2014 Edition), Edward N. Zalta (ed.). http://plato.stanford.edu/archives/spr2014/entries/ emotion.

Dingemanns, G. 2012. Het brein geeft te denken. Free Musketeers: Zoetermeer

LeDoux, J 1996. The Emotional Brain. The mysterious underpinnings of emotional life. New York: Simon \& Schuster Paperbacks.

Mosca, A 2000. Review essay: Antonia Damasio's The Feeling of What Happens. PSYCHE, 6(10). http://psyche.cs.monash.edu.au/v6/psyche-6-10-mosca.html

Oatley, K 1997. Survival of the cowardly. New Scientist, 4 January. http://www.cns. nyu.edu/home/ledoux/the emotional brain/book newsci.htm

Pascal, B 1954 [1670]. Pascal's Pensees. Introduction by T S Eliot. Translated by William Finlayson Trotter. New York: Dutton. 
Stoker, W 2006. Is faith rational? Leuven: Peters.

Veldsman, DP 2013. In vriendskap met Darwin in die Christelike ontwerp van 'n antropologie? HTS Theological Studies 69(1), Art. \#1374. http://dx.doi. org/10.4102/ hts.v69i1.1374

\section{KEY WORDS}

Blaise Pascal

Wessel Stoker

Joseph LeDoux

Antonia Damasio

Emotion

Mood

evolutionary biology

neurosciences

evolutionary theology

affective-cognitive dimension of personhood

\section{CONTACT DETAILS}

Daniël P Veldsman

Professor and Head of Department,

Dept of Dogmatics and Christian Ethics

University of Pretoria

Pretoria

South Africa

Dept of Dogmatics and Christian Ethics,

Faculty of Theology,

University of Pretoria

0002 Pretoria

South Africa

Tel: RSA + 12 + 4205391 / Cell: 0823080414

Email: danie.veldsman@up.ac.za 
